\title{
Uma análise da Lei 13.415/17: o novo Ensino Médio e o lugar da Filosofia no Currículo
}

\author{
Ananalysis of Law 13.415/17: the new High School and the place of \\ Philosophy in the Curriculum
}

\author{
Rafael de Barros \\ Professor mestre da Secretaria de Educação do Estado do Paraná, Jacarezinho, \\ PR, Brasil \\ rafaeldebarros.tometeixeira@gmail.com - https://orcid.org/0000-0003-1363-7580
}

Recebido em 27 de agosto de 2021

Aprovado em 17 de outubro de 2021

Publicado em 30 de dezembro de 2021

RESUMO: Esta pesquisa tem como objetivo contribuir para o debate acerca da contrarreforma do Ensino Médio e seus impactos sobre o currículo, sobretudo no que diz respeito à formação filosófica. Dessa forma, teve como problema a análise do lugar reservado pela Lei 13.415/17 ao ensino de filosofia, visando apontar os movimentos de produção do texto da política educacional, os interesses e sujeitos que participaram do debate. Para tanto, utilizou-se da pesquisa documental e bibliográfica por meio de levantamento realizado sobre as pesquisas acerca do tema. A pesquisa aponta que a Contrarreforma do Ensino Médio, ao não representar as demandas reais do alunado, profissionais e pesquisadores deste nível da Educação Básica e, visando o atendimento das demandas do mercado, a manutenção e reprodução da estrutura social vigente, representa um retrocesso no que diz respeito às políticas curriculares para o Ensino Médio, principalmente no tocante ao espaço reservado a filosofia, conquistado após anos de luta política de profissionais, pesquisadores e alunos, implicando na perda do direito a uma educação filosófica qualificada.

Palavras-chave: Lei 13.415/17; Currículo; Reforma do Ensino Médio; Ensino de Filosofia.

\begin{abstract}
This research aims to contribute to the debate about the counter-reform of high school and its impacts on the curriculum, especially with regard to philosophical teaching. Thus, the problem was the analysis of the place reserved by Law $13,415 / 17$ for the teaching of philosophy, aiming to point out the movements in the production of the text of the educational policy, the interests and subjects that participated in the debate. For this purpose, documentary and bibliographic research was used through a survey carried out on research on the subject. The research points out that the Counter-Reform of High School, by not representing the real demands of students, professionals and researchers at this level of Basic Education and, aiming to meet the demands of the market, the maintenance and reproduction of the current social structure, represents a setback in the with regard to curricular policies for High School, especially with regard to the space reserved for philosophy, conquered after years of political struggle by professionals, researchers and students, implying the loss of the right to a qualified philosophical education.
\end{abstract}

Keywords: Law 13,415/17; Curriculum; High School Reform; Teaching of Philosophy. 


\section{Introdução}

A Lei 13.415/17, imprimindo profundas alterações à Lei de Diretrizes e Bases da Educação Nacional, LDB n 9.393 de 20 de dezembro de 1996, reconfigura o Ensino Médio brasileiro, assim como revoga a alteração da LDB 9.394/96 pela Lei 11.684 de 2 de junho de 2008, que estabelecia as diretrizes e bases da educação nacional para incluir a Filosofia e a Sociologia como disciplinas obrigatórias nos currículos do ensino médio" (BRASIL, 2008).

Nesse cenário, essa pesquisa objetiva realizar um estudo analítico crítico dessa política educacional, no sentido de compreender o teor de tais mudanças, tendo em vista os interesses e princípios intrínsecos em seu conteúdo, apontar os sujeitos partícipes do processo, assim como indicar as consequências práticas derivadas de sua efetivação.

O foco da análise são três questões que nortearam a pesquisa, a saber: 1) Que documentos nortearam a Lei 13.415/17? 2) Que interesses estão intrínsecos no conteúdo do documento? e, 3) Quais as consequências práticas da efetivação da Lei 13.415/7, sobretudo para o ensino de filosofia?

O trabalho divide-se em três momentos, todas eles tendo como referência três categorias de análise que podem ser expostas da seguinte forma: $1^{\circ}$ ) Alteração da carga horária; $2^{\circ}$ ) arquitetura curricular e, $3^{\circ}$ ) lugar da filosofia no currículo.

A primeira parte do trabalho realiza uma análise do PL 6.840/13, tendo como objetivo compreender que mudanças ele buscava imprimir ao Ensino Médio, tendo em vista as categorias de análise supracitadas.

Em sua segunda parte, objetiva-se apresentar o contexto geral da retomada dos debates acerca do Ensino Médio, evidenciando o caráter impositivo da Medida Provisória 746/16, procedendo na análise comparativa da Medida Provisória com o PL 6840/13, apontando as principais mudanças no que diz respeito aos pontos propostos para análise.

A última etapa da pesquisa centra-se na análise da Lei 13.415/17, e objetiva apontar os interesses nela intrínsecos e, a partir da análise de seu texto 
compreender suas proposições referentes à carga horária para o Ensino Médio, à organização curricular e, sobretudo, as implicações da Lei 13.415/17 sobre o ensino e lugar da filosofia no currículo da Educação Básica.

A análise documental e bibliográfica objetiva nos possibilitar realizar diagnóstico acerca da atual conjuntura, de perda de espaço da filosofia no currículo, haja vista a Instrução Normativa Conjunta n. 011/2020 - DEDUC/DPGE/SEED, que diminui a carga horária da disciplina em cinquenta por cento em toda a rede pública do estado do Paraná, ação que pode se tornar regra geral após implementação das mudanças propostas pela contrarreforma.

\title{
O PL 6.840/13 e o início dos debates acerca do Ensino Médio
}

A Lei 13.415 de 16 de fevereiro de 2017, também conhecida como Lei da Reforma do Ensino Médio, consolidou, com algumas alterações, o que estava proposto na Medida Provisória 746 de 22 de setembro de 2016, no entanto o germe de tais alterações já se fazia presente no Projeto de Lei 6.840, apresentado pela Comissão Especial em 27 de novembro de 2011.

\begin{abstract}
O PL 6840/13 tinha sido fruto de mais de 17 meses de trabalho da Comissão Especial destinada a promover Estudos e Proposições para o Ensino Médio (CEENSI) que buscou propor alternativas e novas possibilidades formativas para o Ensino Médio, em debates com representantes de diversos órgãos do Poder Executivo Federal, associações estudantis, sindicatos, Secretarias Estaduais de Educação, gestores de ensino, pesquisadores e especialistas da área educacional (PEREIRA, 2019, p. 45).
\end{abstract}

Tendo como relator o Deputado Wilson Filho, o PL. 6.840/13 objetivava:

Altera a Lei $n^{\circ}$ 9.394, de 20 de dezembro de 1996, que estabelecia as diretrizes e bases da educação nacional, para instituir a jornada em tempo integral no ensino médio, dispor sobre a organização dos currículos do ensino médio em áreas do conhecimento e dá outras providências" (BRASIL, 2013).

Para fins de compreensão do caráter das mudanças propostas pelo PL $\mathrm{n}^{\circ}$. 6.840/13, cita-se os principais artigos referentes à sua redação, tendo como 
referência três categorias de análise, a saber: $1^{\circ}$ ) alteração da carga horária; $2^{\circ}$ ) arquitetura curricular e, $3^{\circ}$ ) lugar da filosofia no currículo.

Com relação à carga horária para o Ensino Médio, a Lei de Diretrizes e Bases para Educação Nacional, Lei n. 9.394/96 (LDB/96), em seu Art. 24, inciso I, previa que "a carga horária mínima anual será de oitocentas horas, distribuídas por um mínimo de duzentos dias de efetivo trabalho escolar, excluído o tempo reservado aos exames finais, quando houver" (BRASIL, 96), com o PL. 6.840/13, a carga horária destinada ao Ensino Médio seria aumentada, e o Art. 24 alterado, passando a ter a seguinte redação: "I - a carga horária mínima anual será de oitocentas horas, no ensino fundamental, e de mil e quatrocentas horas, no ensino médio, distribuídas por um mínimo de duzentos dias de efetivo trabalho escolar, excluído o tempo reservado aos exames finais, quando houver" (BRASIL, 2013), desta forma o Ensino Médio passaria a contar com uma carga horária de 1.400 horas anuais, enquanto o ensino fundamental e infantil continuariam com 800 horas anuais.

Nesse sentido, no Art. $2^{\circ}$ o PL. 6.840/13 ainda previa a inclusão dos Artigos 35-A, 35-B e 36-E, esse último estabelecia que: "A jornada escolar no ensino médio incluirá pelo menos sete horas de trabalho efetivo em sala de aula, sendo progressivamente ampliado o período de permanência na escola, a critério dos sistemas de ensino" (BRASIL, 2013), dessa forma, viabilizava-se o aumento do tempo de permanência, o aumento do número de aulas e a possibilidade de dedicação exclusiva do docente.

Vale destacar a preocupação do PL. 6.840/13 com o Ensino Médio noturno, que em seu Art. $2^{\circ}$ incluía à LDB 9.394/96 o Art. 35-B, segundo o qual:

O ensino médio noturno, respeitadas as formas de organização previstas nesta Lei, observará a carga horária total mínima de 4.200 (quatro mil e duzentas) horas, sendo 3.200 (três mil e duzentas) horas desenvolvidas ao longo de quatro anos, mediante jornada escolar de pelo menos quatro horas de trabalho efetivo em sala de aula, e 1.000 (mil) horas a serem complementadas a critério dos sistemas de ensino (BRASIL, 2013).

Segundo o Art. 35-B, o Ensino Médio noturno também deveria ter sua carga horária aumentada, no entanto o período de conclusão desta etapa da educação se estenderia de três para quatro anos, sendo permitido somente a alunos com idade 
superior a dezoito anos. Ainda sobre o aumento da jornada escolar, o PL.6.840/13, prevê recursos oriundos do Fundo de Manutenção e Desenvolvimento da Educação Básica e de Valorização dos Profissionais da Educação (FUNDEB).

Com relação à arquitetura curricular, o PL 6.840/13 dava nova redação ao Art. 36 da LDB 9.394/96, que deveria receber nova redação, passando a determinar que:

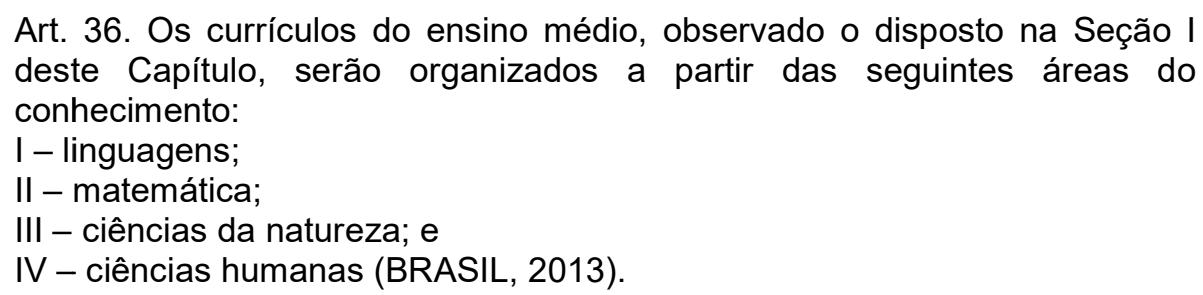

Com a alteração, o currículo deveria ser organizado por áreas do conhecimento em que cada componente curricular se enquadraria tendo em vista sua especificidade. Como justificativa para tal mudança o relato do CEENSI, o Deputado Wilson Filho, afirma que:

\begin{abstract}
A necessidade de readequação curricular no ensino médio, de forma a torná-lo atraente para os jovens e possibilitar sua inserção no mercado de trabalho, sem que isso signifique o abandono da escola, foi, sem dúvida, o ponto mais debatido nas reuniões da CEENSI. O consenso foi de que o atual currículo do ensino médio é ultrapassado, extremamente carregado, com excesso de conteúdo, formal, padronizado, com muitas disciplinas obrigatórias numa dinâmica que não reconhece as diferenças individuais e geográficas dos alunos. Há que se ampliarem as possibilidades formativas do ensino médio, de modo a torná-lo adequado às necessidades do jovem de hoje, atraindo-o para a escola (BRASIL, 2013).
\end{abstract}

A justificativa de que há um número "exagerado" de disciplinas obrigatórias e que havia a necessidade de apontar novas perspectivas para os jovens, no sentido de apontar possibilidades formativas especificas de acordo com suas áreas de interesse fora, novamente, utilizada para afirmar a necessidade da reforma na apresentação da MP nº 746 em 2016.

Outro ponto que merece atenção está exposto pelo Relator do CEENSI, Deputado Wilson Filho, na justificativa do PL 6.840/16, onde afirma que: 
propomos a primeira alteração na LDB, de forma que os currículos do ensino médio sejam organizados por áreas do conhecimento (linguagens, matemática, ciências da natureza e ciências humanas), priorizando a interdisciplinaridade, a transversalidade e a maior interação e articulação entre os diferentes componentes e conteúdos curriculares (BRASIL, 2013).

Com foco na organização curricular na interdisciplinaridade, transversalidade e na interação entre componentes curriculares, o PL 6.840/13 não descarta a necessidade de preservação da especificidade de cada um dos componentes curriculares, não implicando a organização por área do conhecimento na diluição dos componentes curriculares em itinerários formativos tal qual se observa na proposta da Lei $13.415 / 17$.

Nesse contexto, o PL. 6.840/13 altera o que foi estabelecido pela Lei 11.684 de 2 de junho de 2008 que, ao alterar o inciso IV, do Art. 36 da LDB 9.394/96, estabelecia que: "serão incluídas a Filosofia e a Sociologia como disciplinas obrigatórias em todas as séries do ensino médio" (BRASIL, 2008).

Com tal alteração, o PL 6.840/13, inclui ao Art. 36 o parágrafo $1^{\circ}$, segundo o qual:

\begin{abstract}
A base nacional comum dos currículos do ensino médio compreenderá, entre seus componentes e conteúdos obrigatórios, o estudo da língua portuguesa; da matemática; do conhecimento do mundo físico e natural; da Filosofia e da Sociologia; da realidade social e política, especialmente do Brasil; e uma língua estrangeira moderna, além daquela adotada na parte diversificada, conforme dispõe o art. 26, $\S 5^{\circ}$ (BRASIL, 2013).
\end{abstract}

Nota-se que, do ponto de vista prático, não haveria nenhum prejuízo ao ensino de filosofia e ao seu lugar no currículo, sendo apresentada no documento como componente curricular obrigatório do ensino médio. Desta forma, mesmo com a alteração na LDB, o PL. 6.840/13, não representava grandes transformações na arquitetura curricular, sendo preservado o lugar da filosofia no rol das disciplinas obrigatórias, estando sua maior alteração centrada na carga horária. 


\section{A Medida Provisória n. 746/17: continuidades, contradições e interesses}

O ressurgimento do tema da Reforma do Ensino Médio se deu a partir da MP $n^{\circ} 746 / 16$, após apresentação feita por José Mendonça Bezerra Filho, do documento denominado Exposição de Motivos (EM n 00084/2016/MEC), "no qual constavam as justificativas para a aprovação da Medida Provisória $n^{\circ} 746 / 2016$, que alterava a LDB 9394/96" (PEREIRA, 2019, p. 46).

A volta a temática da Reforma do Ensino Médio por meio de Medida Provisória causou intensos movimentos em sinal de desacordo por parte de Movimentos Estudantis, sindicatos de trabalhadores da educação e pesquisadores da área, que viram, na Medida Provisória, um descaso com relação às discussões realizadas desde o PL 6.840/13

Tão logo a MP $746 / 16$ foi aprovada, houve manifestaçães de diversas
entidades educacionais sobre a tramitação da reforma, entre elas:
Associação Nacional de Pós-Graduação e Pesquisa em Educação
(ANPEd); Conferência Nacional dos Trabalhadores em Educação (CNTE);
Procuradoria Federal dos Direitos do Cidadão (PFDC); Sociedade Brasileira
de Sociologia (SBS); Colégio Brasileiro de Ciência do Esporte (CBCE);
União Brasileira de Estudantes Secundaristas (UBES); Associação
Brasileira de Hispanistas (ABH); $5^{\circ}$ Encontro Estadual de Ensino de
Sociologia / RJ; Associação Brasileira de Pesquisa e Pós-Graduação em
Artes Cênicas (ABRACE); Fórum Nacional de Educação (FNE); III
Intercrítica (Intercâmbio Nacional dos Núcleos de Pesquisa em Trabalho e
Educação); Ação Educativa sobre a Reforma no Ensino Médio; Frente
Paraibana Em Defesa Da Escola Sem Mordaça; Associação Brasileira de
Educação Musical (ABEM); Associação Brasileira ABRAPEC; Sociedade
Brasileira de Física (SBF); Sociedade Brasileira de Química (SBQ);
Associação de Linguística Aplicada do Brasil (ALAB) (PEREIRA, 2019, p.
46).

Tais mobilizações ilustravam o clima de desconformidade e descontentamento com relação ao texto da MP 746/16 que, mesmo tendo como referência as discussões realizadas em 2013, no processo do PL 6.840, apresentava uma redação elitista e impositiva, isto é, um texto construído sem o processo de escuta de tais entidades, fato que, naturalmente, causou movimentos contrários e reivindicatórios (CAETANO, 2019).

Com a Comissão Mista, presidida pelo Deputado Izalci Lucas, e tendo como relator o Senador Pedro Chaves, participaram nas audiências profissionais da 
educação, pesquisadores, representantes do MEC e de grupos privados, além de representações estudantis. No entanto, muito embora a comissão contasse com a participação de variados grupos ligados e interessados no tema da educação, seus posicionamentos foram deixados de lado na composição do texto, sendo atendidas reivindicações básicas que, distorcidas, mais reforçavam o caráter elitista da Medida Provisória que contribuíam para o atendimento das demandas populares (CAETANO, 2019).

Eclodem, entre os anos de 2016 e 2017, inicialmente nos estados do Paraná e São Paulo, manifestações de iniciativa dos estudantes secundaristas em sinal de desacordo com a proposta e, sobretudo, como a PEC 241.

[...] nesses movimentos por meio das Associações Estudantis, Grêmios, e de movimentos tais como o Movimento Todos pela Educação. Em 2016 e 2017, estudantes foram às ruas se manifestando contra as reformas no ensino médio (MP 746/16), contra o projeto "Escola Sem Partido", contra a Proposta de Emenda Constitucional (PEC 241), que limita os investimentos na educação. Participaram também de ocupações de escolas e de mobilizações pela educação. Porém, apesar de várias legislações e políticas educacionais implementadas, ainda não há clareza sobre a definição da identidade desse nível de ensino (PEREIRA, 2019, p.10).

Muito embora as mobilizações tivessem sido reconhecidas como legítimas, no sentido de que representavam os interesses reais do alunado do Ensino Médio e reafirmavam a necessidade de mudanças nesse nível da Educação Básica, as tomadas de decisão se deram na contramão das demandas levantadas pelos movimentos juvenis.

Além dos jovens secundaristas, houve movimentos de entidades de pesquisa ligadas à educação, apontando suas leituras críticas do texto, pontos de tensão e o desacordo com o proposto.

Para a Associação Nacional de Pós-Graduação e Pesquisa em Educação (ANPEd), assim como para o Fórum Nacional da Educação e demais organizações desse campo, o recurso da medida provisória n. 746/2016 reflete a postura autoritária de um governo que não foi legitimado pelo voto, configurando-se, segundo Simões (2016), como instrumento abusivo "sem precedentes na história brasileira após a democratização (LIMA, M. MACIEL, S. 2018, p.10). 
A escolha da Medida Provisória como meio político para levar a debate a MP 746/16, sob a justificativa da urgência do tema, foi duramente criticada durante as discussões em percurso.

Assim, a Reforma pretendida à época, por meio de Medida Provisória, não levou em consideração a necessidade de políticas de fomento para materialização das mudanças por ela propostas, ficando o aumento progressivo da carga horária, a adequação à oferta de itinerários formativos, principalmente o profissionalizante, dependentes das possibilidades e necessidades de cada sistema de ensino, delegando a esses a adequação ao que a MP 746/16 impusera, acentua ainda mais as distinções e disparidades referentes às escolas públicas e privadas, tendo como consequência a vantagem formativa para alunos da rede privada de ensino, implicando na criação de duas escolas, uma destinada aos ricos e outra à classe trabalhadora, dificultando para esses formarem-se integralmente tal como possibilitado aos ricos (FRIGOTTO, 2016).

Para fins de exposição e compreensão da MP 746/16 tomamos como referência as três categorias de análise, anteriormente citadas, comparando o texto da Medida Provisória com o proposto pelo PL 6.840/13. Com relação às categorias cabe elencá-las: $1^{\circ}$ ) na alteração da carga horária; $2^{\circ}$ ) arquitetura curricular e $3^{\circ}$ ) lugar da filosofia no currículo.

No que concerne ao aumento progressivo da carga horária para o Ensino Médio a MP 746/16, em seu Art. 1º, define que ao Art. 24 da LDB 9.394/96seria alterado, passando a ter a seguinte redação:

Parágrafo único. A carga horária mínima anual de que trata o inciso I do caput deverá ser progressivamente ampliada, no ensino médio, para mil e quatrocentas horas, observadas as normas do respectivo sistema de ensino e de acordo com as diretrizes, os objetivos, as metas e as estratégias de implementação estabelecidos no Plano Nacional de Educação." (NR) (BRASIL, 2016, s/p).

Com relação à ampliação da carga horária, a MP. 746/16, não difere da proposta apresentada em 2013 pelo PL.6.840/13. Nota-se, que, no entanto, a ampliação da carga horária no Ensino Médio é prejudicial e excludente no sentido de que grande parcela dos jovens matriculados no Ensino Médio está na Rede Pública 
e, conciliam sua formação com a vida profissional. Dessa forma, a ampliação tende a culminar no aumento do número de evasão dos alunos da Rede Pública, em virtude da necessidade do trabalho remunerado.

Em seu Art. 19 , a MP 746/16 ainda prevê a alteração do Art. 36 da LDB 9.394/96 e a inclusão, no mesmo, do parágrafo $6^{\circ}$, segundo qual: "A carga horária destinada ao cumprimento da Base Nacional Comum Curricular não poderá ser superior a mil e duzentas horas da carga horária total do ensino médio, de acordo com a definição dos sistemas de ensino" (BRASIL, 2016).

Com tal medida, a reforma, que teria como objetivo fundamental implementar o Ensino Médio em Tempo Integral por meio do aumento de 800 horas para um total de 1400 horas por ano letivo, configurando um aumento da carga horária total de 2.400 horas, distribuídas em três anos, para 4.200 horas, vai na contramão do que propõe, uma vez que reduz a formação comum.

Ao estabelecer que a formação básica, garantida pela implementação da Base Nacional Comum Curricular, não poderá ser superior a mil e duzentas (1.200h) da carga horária total do Ensino Médio, restando um total de três mil horas para itinerários formativos, a MP 746/16 impossibilita uma formação única e igualitária aos jovens do Ensino Médio, sobretudo à aqueles matriculados na rede Pública de Ensino, uma vez que, por motivo da PEC 241/16, convertida na Emenda constitucional $n^{\circ} .95$ em 15 de dezembro de 2016, que limita os investimentos do Poder Público por um período de 20 anos, a oferta dos itinerários formativos pelas escolas das Redes Públicas poderá ocorrer de modo precário e único, impossibilitando aos alunos da Escola Pública a possibilidade da escolha do itinerário a ser cumprido. Realidade agravada pelo fato de $85 \%$ das matrículas do Ensino Médio pertencer à rede pública de ensino (BRASIL, 2016).

Com relação à arquitetura curricular, a MP 746 propõe, em seu Art. $1^{\circ}$, a alteração dos incisos I a V do Art. 36 da LDB 9.394/96, dando a esse a seguinte redação: 
Art. 36. O currículo do ensino médio será composto pela Base Nacional Comum Curricular e por itinerários formativos específicos, a serem definidos pelos sistemas de ensino, com ênfase nas seguintes áreas de conhecimento ou de atuação profissional:

I - linguagens;

II - matemática;

III - ciências da natureza;

IV - ciências humanas; e

$\mathrm{V}$ - formação técnica e profissional.

$\S 1^{\circ}$ Os sistemas de ensino poderão compor os seus currículos com base em mais de uma área prevista nos incisos I a V do caput (BRASIL, 2016, $\mathrm{s} / \mathrm{p})$.

Uma das justificativas apontadas para a mudança na LDB foi apresentada pelo Ministro de Estado da Educação, José Mendonça Bezerra Filho, em 15 de setembro de 2016, segundo o Ministro:

\begin{abstract}
Atualmente o ensino médio possui um currículo extenso, superficial e fragmentado, que não dialoga com a juventude, com o setor produtivo, tampouco com as demandas do século XXI. Uma pesquisa realizada pelo Centro Brasileiro de Análise e Planejamento - Cebrap, com o apoio da Fundação Victor Civita - FVC, evidenciou que os jovens de baixa renda não veem sentido no que a escola ensina (BRASIL, 2016, s/p)
\end{abstract}

Novamente o que se nota são ataques ao currículo e à configuração do Ensino Médio, não havendo observância dos reais problemas que assolam este nível da Educação Básica como, por exemplo: escolas sucateadas e com péssimos estados de conservação devido à falta de repasse de recursos; falta de estrutura para aulas que necessitam de laboratórios, quadras poliesportivas, bibliotecas, salas de informática com equipamentos adequados e funcionais; transporte escolar inadequado e com precário estado de conservação e manutenção. Todos esses fatores são os que realmente comprometem a formação e futuro dos jovens.

A MP 746/16, ao propor a reorganização curricular do Ensino Médio, ignora as demandas reais dessa etapa da Educação Básica, e elucida o fato de a reforma ter em mira o atendimento das demandas do mercado e, como beneficiários grupos privatistas ligados da educação. Nesse sentido, torna-se exemplar a participação do Reitor da Universidade Estácio de Sá, do Reitor da Unicesumar, e do Superintendente Executivo do Instituto Unibanco, na Audiência pública, realizada na $4^{a}$ reunião da Comissão Mista, em 08 de novembro de 2016. 
Com relação ao ensino de filosofia, a MP 746/16 não apresenta nenhuma proposta em seu texto original, apresentado em 22 de setembro de 2016. Sobre o tema, a Comissão Mista apresenta o Parecer n 95, em 30 de novembro de 2016, e esclarece que:

\begin{abstract}
O art. $1^{\circ}$ da MPV $n^{\circ} 746$, de 2016, também altera o art. 36 da Lei $n^{\circ} 9.394$, de 1996. Assim, o caput passa a prever que o currículo do ensino médio será composto pela BNCC e por itinerários formativos específicos a serem definidos pelos sistemas de ensino, [...]. Dessa forma, não mais tem validade o antigo texto do inciso IV, que previa filosofia e sociologia como disciplinas obrigatórias do ensino médio (revogou-se tacitamente, portanto, a Lei $n^{\circ}$ 11.684, de 2 de junho de 2008) (BRASIL, 2016, s/p).
\end{abstract}

Como forma de resistência à retirada da filosofia do Ensino Médio brasileiro foram apresentadas à MP 746/16 as Emendas $n^{\circ}$. 04, 08 e 24 pelo Dep. André Figueiredo; Emenda $\mathrm{n}^{\circ}$. 11, do Sen. Paulo Bauer; Emenda $\mathrm{n}^{\circ}$. 16, da Sen. Vanessa Grazziotin; Emenda nº 89, do Dep. João F Coutinho; Emenda $n^{\circ}$. 102, do Dep. Átila Lira; Emenda $n^{\circ} .139$, do Sen. Cristovam Buarque; Emenda $n^{\circ} .221$, do Dep. Arnaldo Jordy; Emenda n. 252, do Dep. Sérgio Souza; Emenda n. 267, do Dep. João Daniel; Emenda n. 334, do Dep. Pedro Uczai; Emenda n. 342, do Dep. Bebeto; Emenda $n^{\circ}$. 353, do Dep. Danilo Cabral; Emenda n. 384, do Dep. Alfredo Kaefer; Emenda $n^{\circ} .425$, do Dep. Ezequiel Teixeira; Emenda $n^{\circ}$. 488, do Dep Stefano Aguiar e a Emenda n 503 da Deputada Maria do Rosário Nunes.

Após a apresentação de 18 Emendas apresentadas por Senadores e Deputados Federais em defesa da permanência e obrigatoriedade da filosofia no Ensino Médio, além das manifestações da comunidade em geral, esperava-se, como caminho lógico rumo a consolidação de um processo democrático referente às tomadas de decisão ligadas à Reforma do Ensino Médio, que as reivindicações fossem acatadas e que a filosofia, assim como a sociologia, fossem incorporadas à MP 746/16 como componentes curriculares obrigatórios. No entanto, na contramão do sistema democrático e evidenciando ainda mais o caráter autoritário a MP 746/16, o Parecer n 95 da Comissão Mista, tendo como relator o Senador Pedro Chaves, afirma que: "Mesmo com expressiva quantidade de emendas parlamentares e manifestações dos movimentos sociais e especialistas ouvidos na comissão, o 
relator manteve o fim da obrigatoriedade do ensino de filosofia e sociologia no ensino médio" (BRASIL, 2016, p.07).

A disciplina volta ao currículo somente após mobilizações de parlamentares e da comunidade e, no dia 14 de dezembro de 2016, é apresentado o texto aprovado pela Câmara dos Deputados, que incluindo ao Art. $1^{\circ}$, da MP746/16, que estabelecia a inclusão do Art. 35-A a LDB 9.394/96, a inclusão do $\S 2^{\circ}$ ao Art. 35-A, que passou a ter a seguinte redação: " $§ 2^{\circ}$ A Base Nacional Comum Curricular referente ao ensino médio incluirá obrigatoriamente estudos e práticas de educação física, arte, sociologia e filosofia" (BRASIL, 2016).

Com a inclusão do parágrafo $2^{\circ}$, o ensino de filosofia passa a ser obrigatório na Base nacional comum curricular, no entanto, a falta de clareza com relação ao modo como sua inclusão se dará acarreta problemas com relação à prática do ensino da disciplina, que pode passar a ser oferecida como tema transversal e não propriamente como componente curricular. Outra questão que vale ser relembrada é o fato de que a Base Nacional Comum Curricular (BNCC) não poderá ultrapassar um total de 1.200 horas do total de 4.200 horas, segundo determinação da MP746/16, fato que tende a redução da carga horária destinada ao ensino de filosofia, fato já observado no Estado do Paraná.

Com poucas alterações, a MP 746/16 foi aprovada no Senado Federal em 13 de fevereiro de 2017, sendo convertida na Lei 13.415 em 16 de fevereiro de 2017, e sancionada pelo Presidente da República, publicada no Diário Oficial da União em 17 de fevereiro de 2017.

\section{A Lei $13.415 / 17$ e o lugar da Filosofia no currículo}

A sansão da Lei 13.415, em 16 de fevereiro de 2017, conhecida como "lei da reforma do Ensino Médio", suscitou e ainda motiva acalorados debates entorno da formação Média brasileira. Os debates, marcados por posicionamentos inconciliáveis, se dão no sentido da busca pelo entendimento dos interesses que nortearam as decisões referentes ao futuro do Ensino de Nível Médio brasileiro, interesses que, longe de estarem em acordo com as demandas sociais, dado 
provado pela ocupação de escolas nos períodos de votação, assim como pelo ínfimo espaço aberto às consultas públicas, acabaram por ser levados à cabo com a publicação da Lei no Diário Oficial da União (DOU - Seção 1), em 17 de fevereiro de 2017.

\begin{abstract}
É importante destacar que as mudanças que ficaram estabelecidas na Lei 13.415/17 em relação ao que estava proposto na MP 746/16 foram uma conquista de movimentos de professores, estudantes e entidades ligadas à educação, como ANPED (Associação Nacional de Pós-graduação e Pesquisa em Educação), o CEDES (Centro de Estudos Educação e Sociedade, ANFOPE (Associação Nacional pela Formação dos Profissionais da Educação), CONIF (Conselho Nacional das Instituições da Rede Federal de Educação Profissional Científica e Tecnológica), CNTE (Confederação Nacional dos Trabalhadores em Educação), dentre outros, que engajaram em manifestações em prol da educação (PEREIRA, 2019, p. 50).
\end{abstract}

A Lei 13.415/17, em seu Art.26, § 10, prevê que "a inclusão de novos componentes curriculares de caráter obrigatório na Base Nacional Comum Curricular dependerá de aprovação do Conselho Nacional de Educação e de homologação pelo Ministro de Estado da Educação" (BRASIL, 2017), deixando de lado, na construção do currículo, as entidades civis ligadas à educação como as associações de pesquisadores, grupos estudantis, associações de profissionais da educação, o que evidencia o caráter antidemocrático da reforma e seu alinhamento com um pensamento hegemônico que atende aos interesses das classes dirigentes.

Outro ponto que nos interessa é a análise do lugar reservado a filosofia no contexto da Reforma do Ensino Médio, levada a cabo pela Lei 13.415/17. Em sua redação a Lei 13.415/17 prevê, em seu Art. 35 - A, $\S 2^{\circ}$, que "A Base Nacional Comum Curricular referente ao ensino médio incluirá obrigatoriamente estudos e práticas de educação física, arte, sociologia e filosofia” (BRASIL, 2017). A redação do texto, ao apresentar a inclusão da filosofia na forma de estudos e práticas, a deixa em desamparo, uma vez que não há garantias de que esta, assim como a sociologia, arte e educação física sejam integradas à Base Nacional Comum Curricular na forma de componentes curriculares específicos, abrindo margem para sua diluição na forma de abordagens de estudo de temas gerais presentes nos itinerários formativos. 


\begin{abstract}
A olhos descuidados, uma leitura rápida do artigo 35-A da mesma lei pode levar ao entendimento de que sociologia e filosofia foram reinseridas como obrigatórias na BNCC. No entanto, há que se ponderar que não é exatamente isso que o texto da lei assegura, pois o que deve ser garantido são estudos e práticas, e não a inclusão obrigatória do componente curricular (LIMA, M. MACIEL, S. 2018, p.14).
\end{abstract}

Uma vez que não se define com clareza o que se entende como "estudo e práticas", os Estados, influenciados pelo preconceito produzido pelos grupos neoconservadores ligados ao poder Executivo do Presidente em exercício, Jair Messias Bolsonaro, e mediado na mass media, a optar por retirar a disciplina de seus cursos ou imputá-la um tratamento transversal, o que causaria um prejuízo formativo dos egressos do Ensino Médio, segundo (LIMA; MACIEL, 2018):

Não menos importante, no novo Ensino Médio anunciado, a formação ética, estética e científica dos estudantes sai empobrecida, ainda mais quando a medida se refere a "estudos e práticas", mudando o sentido de disciplinas, como são os casos de sociologia e filosofia. (FaE/UFMG, 2017. Apud, LIMA; MACIEL. 2018, p.14).

Ademais, o fim da obrigatoriedade das disciplinas de arte, educação física, filosofia e sociologia, justificadas pelo número excessivo de disciplinas curriculares mascara o verdadeiro interesse com a nova arquitetura curricular, isto é, o fim das disciplinas com potencial para contribuir com a formação crítica, para abrir espaço para a integração de outras, de caráter utilitário e ideologicamente voltadas aos interesses das classes hegemônicas, nesse sentido são exemplares os caso dos componentes: Projeto de Vida e Empreendedorismo.

Para Frigotto (2016), a retirada de disciplinas pautada em um discurso de que o ensino médio carrega muitas disciplinas máscara o que de fato se quer excluir do currículo escolar: as disciplinas de sociologia, filosofia, a redução de geografia e história. Sob o argumento de que o aluno de hoje é "digital e não aguenta uma escola conteudista", não se leva em conta que o que de verdade os alunos não aguentam mais é uma escola sucateada, sem laboratórios, auditórios, espaços para desenvolvimento de atividades de cultura e lazer, o que ficou claro com o movimento de ocupações das escolas por estudantes do ensino médio, em resposta à reforma promovida pelo Governo Temer, reivindicando nada mais que condições decentes para estudar. (LIMA, M. MACIEL, S. 2018, p.15) 
Ao invés da busca pelo suprimento das demandas reais que se apresentam como causa do fracasso escolar, o que se propõe com a Lei 13.415/17 é uma reforma de caráter ideológico e reducionista, que não toca nos problemas que deveria solucionar.

Nesse sentido, as reformas propostas servem aos interesses do Estado e de grupos privatistas da educação, uma vez que, a PEC 241/55 "guarda intenções mais profundas que apenas reduzir gastos primários (saúde, educação, segurança etc.)" (BRAGA e NAKATANI, 2016, Apud, LIMA; MACIEL, 2018, p. 06). A educação seria, portanto, compreendida, na perspectiva das políticas neoliberais, como gasto que pode ser reduzido ou redirecionado na forma de parcerias com grupos privados da educação.

Também deve ser levado em consideração a redação que se faz presente no Art. 36 da Lei 13.415/17, que versa sobre a organização do Ensino Médio em cinco itinerários formativos:

\footnotetext{
Art. 36. O currículo do ensino médio será composto pela Base Nacional Comum Curricular e por itinerários formativos, que deverão ser organizados por meio da oferta de diferentes arranjos curriculares, conforme a relevância para o contexto local e a possibilidade dos sistemas de ensino, a saber:

I - linguagens e suas tecnologias;

II - matemática e suas tecnologias;

III - ciências da natureza e suas tecnologias;

IV - ciências humanas e sociais aplicadas; $\mathrm{e}$

V - formação técnica e profissional (BRASIL, 2017).
}

Sob a justificativa de que o currículo em vigência está em desacordo com o interesse dos jovens, e é excessivamente extenso, por ser composto de 13 disciplinas, argumenta-se que os itinerários formativos dariam aos jovens possibilidades de escolha, garantindo e incentivando o desenvolvimento autônomo e o protagonismo juvenil no processo de formação. No entanto, conforme aponta (PEREIRA, 2019):

Ao estabelecer que o Ensino Médio tenha uma Base Nacional Comum e Itinerários Formativos, fica clara a intencionalidade governamental de aligeirar e fragmentar a educação com o respaldo da mídia e de alguns estudantes iludidos por força de propagandas enganosas de que teriam direito de escolher o itinerário que tivessem mais afinidade. Enganosa porque os itinerários serão definidos pelas instituições e não pelos estudantes, que ficarão à mercê das possibilidades de cada município (PEREIRA, 2019, p.65). 
Da mesma forma, como implicação da $E C n^{\circ}$. 95/16, as escolas públicas não podem garantir a oferta de todos os cinco itinerários, visto suas privações materiais derivadas da carência de fomento provinda do Estado, tendo de adequar as possibilidades de organização dos itinerários formativos à sua realidade material. $\mathrm{O}$ problema da oferta, potencialmente vivenciado pela escola pública, não se configurará como impedimento às escolas privadas, essas poderão, inclusive com auxílio do Estado, ofertar a seus alunos todos os itinerários formativos, reforçando, como já mencionado, a diferença entre educação para a elite e educação para as classes menos abastadas.

A Reforma do Ensino Médio, desta forma, se apresenta como excludente e pouco preocupada com os interesses da comunidade escolar, sobretudo da Escola Pública visto que, ao aumentar a carga horária para conclusão do Ensino Médio de $800 \mathrm{~h} /$ ano para 1400h/ano, o que representa o aumento de cinco para sete aulas diárias, dificulta aos alunos trabalhadores a frequência escolar.

Outro fator de exclusão é o fato a Lei 13.415/17 determinar carga horária total de $1800 \mathrm{~h}$ destinadas ao cumprimento da Base Nacional Comum Curricular e $2400 \mathrm{~h}$ destinadas à parte diversificada preenchida pelos itinerários formativos, o que vai à contramão da proposta de uma BNCC-EM, uma vez que diminui, ao total do prazo, quando a carga horária for de 4000 horas no total a formação comum, privilegiando os itinerários formativos.

$\mathrm{O} \S 5^{\circ}$ do Art. 35-A estabeleceu que a carga horária destinada à BNCC não poderá ser superior a $1800 \mathrm{~h}$ do total da carga horária do Ensino Médio. Isso significa que com a carga horária de $1000 \mathrm{~h}$ por ano (3000h no curso) a BNCC corresponderá a $60 \%$ do total do currículo. Quando a carga horária for ampliada para $1400 \mathrm{~h}$ anuais (conforme a previsão da Lei) teremos um total de $4200 \mathrm{~h}$ no curso do Ensino Médio e apenas 1800h para a BNCC (carga horária máxima estabelecida para a BNCC), que corresponderá a $43 \%$ do currículo (PEREIRA, 2019, p. 60).

Tal configuração representa barreira para a promoção de uma formação integral, assim como o aprofundamento de um Ensino Médio Unilateral e pouco abrangente. Nesse sentido, se tem em vista a especialização e a formação para o trabalho e as demandas dos processos produtivos do capital, e não a formação 
ampla e abrangente, objeto de reivindicação de especialistas em educação.

Assim, os resultados da implementação da Contrarreforma do Ensino Médio se apresentam como prejudiciais não somente no tocante ao ensino de filosofia e a formação filosófica dos jovens brasileiros, uma vez que seu lugar na arquitetura curricular se vê comprometido e mercê de interesses e interpretações de dirigentes estaduais e sistemas de ensino, um conjunto arranjos curriculares que são "esvaziados de sentido para os estudantes, pois são construídos sem a participação dos mesmos (PEREIRA, 2019, p. 28), indo ao encontro dos interesses da economia e atendimento às adequações demandadas pelos órgãos internacionais como o Banco Mundial e o Fundo Monetário Internacional, tendo em vista o ranqueamento feito a partir de avaliação externas como a PISA.

\section{Considerações finais}

A Lei 13.4115, de 16 de fevereiro de 2017, também conhecida como Lei da Reforma do Ensino Médio, consolidou, com algumas alterações, o que estava proposto na Medida Provisória 746, de 22 de setembro de 2016. No entanto o germe de tais alterações já se fazia presente no Projeto de Lei 6.840, apresentado pela Comissão Especial, em 27 de novembro de 2011, sendo aprovada, por unanimidade, pela Câmara do Deputados, em 16 de dezembro de 2014.

O ressurgimento do tema da Reforma do Ensino Médio se deu a partir da MP $n^{\circ} 746 / 16$, após apresentação feita por José Mendonça Bezerra Filho, do documento denominado Exposição de Motivos (EM nº 00084/2016/MEC), causando intensos movimentos em sinal de desacordo por parte de Movimentos Estudantis, sindicatos de trabalhadores da educação e pesquisadores, que viram na Medida Provisória um descaso com relação às discussões realizadas desde a PL 6.840/13, além de se apresentar como ato antidemocrático tendo em vista a imposição via Medida Provisória.

As mobilizações de entidades estudantis, sindicatos, associações de docentes e pesquisadores apontou o clima de desconformidade e descontentamento com relação ao texto exposto na MP 746/16 que, mesmo tendo como referência as 
discussões realizadas em 2013 no processo do PL 6.840, apresenta uma redação elitista e impositiva, isto é, um texto construído sem o processo de escuta de tais entidades, fato que, naturalmente, causou movimentos contrários e reivindicatórios.

A MP 746/16, ao propor a reorganização curricular do Ensino Médio, tem em vista com o atendimento das demandas do mercado e o beneficiamento de grupos privatistas ligados à educação, nota-se a participação ativa do Reitor da Universidade Estácio de Sá, do Reitor da Unicesumar, e do Superintendente Executivo do Instituto Unibanco, na Audiência pública, realizada na $4^{a}$ reunião da Comissão Mista.

Com relação ao ensino de filosofia, o Parecer da Comissão Mista, Parecer $n^{\circ}$ 95, de 30 de novembro de 2016, esclarece que "não mais tem validade o antigo texto do inciso IV, que previa filosofia e sociologia como disciplinas obrigatórias do ensino médio" (revogou-se tacitamente, portanto, a Lei $\mathrm{n}^{\circ} 11.684$, de 2 de junho de 2008) (BRASIL, 2016).

O Parecer 95, da Comissão Mista, torna clara a exclusão da filosofia enquanto componente curricular obrigatório no Ensino Médio. Como forma de resistência à retirada da filosofia do Ensino Médio brasileiro foram apresentadas Emendas a Medida Provisória em defesa desta.

Após a apresentação de 18 Emendas apresentadas por Senadores e Deputados Federais em defesa da permanência e obrigatoriedade da filosofia no Ensino Médio, além das manifestações da comunidade em geral, esperava-se que as reivindicações fossem acatadas e que a filosofia, assim como a sociologia, fosse incorporada à MP 746/16 como componente curricular obrigatório. No entanto, na contramão do sistema democrático e evidenciando ainda mais o caráter autoritário a MP 746/16, o Parecer n95 da Comissão Mista, tendo como relator o Senador Pedro Chaves, afirma que: "Mesmo com expressiva quantidade de emendas parlamentares e manifestações dos movimentos sociais e especialistas ouvidos na comissão, o relator manteve o fim da obrigatoriedade do ensino de filosofia e sociologia no ensino médio" (BRASIL, 2016, p.07).

Somente depois de mobilizações de parlamentares e da comunidade que, no dia 14 de dezembro de 2016, é apresentado o texto aprovado pela Câmara dos 
Deputados, incluindo ao Art. $1^{\circ}$, da MP746/16, que estabelecia a inclusão do Art. 35A a LDB 9.394/96, a inclusão do $\S 2^{\circ}$ ao Art. 35-A, que passa a ter a seguinte redação: "§ $2^{\circ}$ A Base Nacional Comum Curricular referente ao ensino médio incluirá obrigatoriamente estudos e práticas de educação física, arte, sociologia e filosofia" (BRASIL, 2016).

Com poucas alterações, a MP 746/16 foi aprovada no Senado Federal em 13 de fevereiro de 2017, sendo convertida na Lei 13.415 em 16 de fevereiro de 2017, e sancionada pelo Presidente da República, e publicada no Diário Oficial da União em 17 de fevereiro de 2017.

Com a relação ao lugar reservado à filosofia, a Lei 13.415/17 consolida em seu Art. 35 o que já havia sido proposto na MP 746/16. A redação do texto, ao apresentar a inclusão da filosofia na forma de estudos e práticas, a deixa em desamparo uma vez que não há garantias de que esta seja integrada à BNCC na forma de componentes curriculares específicos, abrindo margem para sua diluição na forma de abordagens de estudo de temas gerais presentes nos itinerários formativos, propostos pelo mesmo Art. 35 - A.

A falta de clareza com relação ao que se define como "estudo e práticas" podem levar os Estados, influenciados pelos vários guias de implementação, produzidos e veiculados por grupos privados que tem interesse na educação, sobretudo a pública, à retirada da disciplina de seus currículos como componente curricular ou diminuição de sua carga horária, como já se observa em alguns Estados como o Paraná.

A pesquisa em questão nos mostrou que a Reforma do Ensino Médio carrega em seu bojo os interesses de grupos privatistas da educação, além dos princípios que norteiam as decisões do Estado característicos de posturas neoliberais, assim a reforma, menos preocupada com as demandas reais do alunado, profissionais e pesquisadores deste nível da Educação Básica, visa o atendimento das demandas do mercado e a manutenção da ordem social desigual e estratificada vigente. 


\section{Referências:}

ANPED. ANPEd e a BNCC: luta, resistência e negação. Rio de Janeiro: ANPED, 2018. Disponível em: https://anped.org.br/content/anped-e-bncc-luta-resistencia-e-negacao. Acesso em: 10 mar. 2021.

BRASIL. Lei $\mathbf{n}^{\circ}$ 9.394, de 20 de dezembro de 1996. Estabelece as diretrizes e bases da educação nacional. Diário Oficial da União, Brasília, DF, 23 dez. 1996. Disponível em: <http://www.planalto.gov.br/ccivil_03/LEIS/L9394.htm>. Acesso em: 15 mai. 2021.

BRASIL. Lei No 11.684, de 2 de junho de 2008. Altera o art. 36 da Lei n. 9.394, de 20 de dezembro de 1996, que estabelece as diretrizes e bases da educação nacional, para incluir a Filosofia e a Sociologia como disciplinas obrigatórias nos currículos do ensino médio. Disponível em: http://www.planalto.gov.br/ccivil_03/_Ato20072010/2008/Lei/L11684.htm. Acesso em: 20 mar. 2021.

BRASIL. Projeto de Lei 6840/2013. Altera a Lei $n^{\circ}$ 9.394, de 20 de dezembro de 1996, que estabelece as diretrizes e bases da educação nacional, para instituir a jornada em tempo integral no ensino médio, dispor sobre a organização dos currículos do ensino médio em áreas do conhecimento e dá outras providências. Câmara dos Deputados. 2013. Disponível em:

https://www.camara.leg.br/proposicoesWeb/fichadetramitacao?idProposicao=60257. Acesso em: 19 mar. 2021

BRASIL. Medida Provisória n $^{\mathbf{7 4 4 6}}$, de 23 de setembro de 2016. Institui a Política de Fomento à Implementação de Escolas de Ensino Médio em Tempo Integral, altera a Lei $n^{\circ}$ 9.394, de 20 de dezembro de 1996, que estabelece as diretrizes e bases da educação nacional, e a Lei no 11.494 de 20 de junho 2007, que regulamenta o Fundo de Manutenção e Desenvolvimento da Educação Básica e de Valorização dos Profissionais da Educação, e dá outras providências. Brasília: Congresso Nacional. 23 set. 2016. Disponível em: https://www.congressonacional.leg.br/materias/medidasprovisorias/-/mpv/126992. Acesso em: 12 mai. 2021.

BRASIL. Lei 13.415/17. Altera as Leis n. ${ }^{\circ}$ 9.394, de 20 de dezembro de 1996, que estabelece as Diretrizes e Bases da Educação Nacional, e 11.494, de 20 de junho 2007, que regulamenta o Fundo de Manutenção e Desenvolvimento da Educação Básica e de Valorização dos Profissionais da Educação, a consolidação das leis do trabalho - CLT, aprovada pelo decreto- lei $n^{\circ} 5.452$, de $1^{\circ}$ de maio de 1943 , e o Decreto-lei $n^{\circ} 236$, de 28 de fevereiro de 1967; revoga a lei $n^{\circ} 11.161$, de 5 de agosto de 2005; e institui a política de fomento à implementação de escolas de ensino médio em tempo integral. Brasília: Senado Federal, 17 de fev. de 2017. Disponível em <http://www2.camara.leg.br/legin/fed/lei/2017/lei-13415-16-fevereiro2017-784336publicacaooriginal-152003-pl.html> Acesso em: 12 de mar. 2021 
BRASIL. Base Nacional Comum Curricular. Brasília: MEC, 2018. Disponível em: http://basenacionalcomum.mec.gov.br/images/historico/BNCC_EnsinoMedio_embaixa_ site_110518.pdf. Acesso em: 17 mai. 2021.

BRASIL. Exposição de Motivos n 00084/2016/MEC. Ministério da Educação. 2016d. Disponível em: https://www.planalto.gov.br/ccivil_03/_Ato2015-2018/2016/Exm/ExmMP-746-16.pdf Acesso em: 10 maio 2012.

BRASIL. Comissão Mista da MPV 746/2016. Parecer, $\mathbf{n}^{\circ} 95$ de 30 de novembro de 2016. Brasília: Senado Federal, 30 nov. 2016c. Disponível em: https://www.camara.leg.br/proposicoesWeb/prop_mostrarintegra?codteor=1512505\&file name=PAR+95+MPV74616+\%3D\%3E+MPV+746/2016. Acesso em: 19 mai. 2021.

CAETANO, M. R. Os sujeitos e a proposta educacional da base nacional comum curricular: entre o público e o privado. Teoria e Prática da Educação, Maringá, v. 22, n.3, p. 118-136, Setembro/Dezembro 2019. Disponível em:

https://periodicos.uem.br/ojs/index.php/TeorPratEduc/article/view/46916. Acesso em: 10 mai. 2021.

FRIGOTTO, G. Reforma de ensino médio do (des) governo de turno: Decreta-se uma escola para os ricos e outra para os pobres. 2016. Disponível em:

http://www.anped.org.br/news/reforma-deensino-medio-do-des-governo-de-turnodecreta-se-uma-escola-para-os-ricos-e-out. Acesso em: 10 jun. 2021.

LIMA, M.; MACIEL, S. L. A reforma do Ensino Médio do governo Temer: corrosão do direito à educação no contexto de crise do capital no Brasil. Revista Brasileira de Educação, Rio de Janeiro RJ, v. 23, p. 1-25, 2018. Disponível em: https://www.scielo.br/pdf/rbedu/v23/1809-449X-rbedu-23-e230058.pd. Acesso em: 10 jun. 2021.

PEREIRA, C. S. M. Reforma do ensino médio - lei 13.415/2017: avanços ou retrocessos na educação? 2019. Dissertação de Mestrado (Mestrado em Educação) Universidade Federal Rural do Rio de Janeiro Instituto de Agronomia, Seropédica, 2019. Disponível em:

https://sucupira.capes.gov.br/sucupira/public/consultas/coleta/trabalhoConclusao/viewTr abalhoConclusao.jsf?popup=true\&id_trabalho=8192863. Acesso em: 10 mai. 2021.

\section{(c) (1) (2)(2)}

This work is licensed under a Creative Commons Attribution-NonCommercial 4.0 International (CC BY-NC 4.0) 